\title{
Shrinkage characteristics of a novel lower contractile acrylic pattern resin
}

\author{
Miki HORI ${ }^{1}$, Tadasuke HORI ${ }^{2}$, Hironao SEKINE², Akimichi MIEKII ${ }^{1}$, Kotaro FUJIMOTO ${ }^{1}$ and Tatsushi KAWAI ${ }^{1,2}$ \\ ${ }^{1}$ Department of Dental Materials Science, School of Dentistry, Aichi Gakuin University, 1-100 Kusumoto-cho, Chikusa-ku, Nagoya, Aichi 464-8650, \\ Japan \\ ${ }^{2}$ Center for Advanced Oral Science, School of Dentistry, Aichi Gakuin University, 1-100 Kusumoto-cho, Chikusa-ku, Nagoya, Aichi 464-8650, \\ Japan \\ Corresponding author, Miki HORI; E-mail: mikihori@dpc.agu.ac.jp
}

\begin{abstract}
Forming models and brazing parts, both of which require high accuracy, are greatly affected the polymerization shrinkage of pattern resin. In 2018, a lower-shrinkage autopolymerizing pattern resin (PRK) was introduced. In this work, we compared the rate of polymerization shrinkage between PRK with that of three autopolymerizing resins — GC Pattern Resin (GPR), Pi-Ku Plast (PIK), and Fixpeed (FIX) — as controls. The shrinkage percentages at 10 min were $7.26 \pm 0.88$ for PRK, $10.78 \pm 2.28$ for GPR, $8.03 \pm 1.08 \%$ for PIK, and 7.46 \pm 1.25 for FIX. The shrinkage of PRK was significantly lower than that of GPR. The lower-shrinkage autopolymerizing resin contains some multifunctional monomer and indicated that the amount of monomer was accordingly reduced from the result of polymer size and abundance ratio. Our results suggested that the monomer component and the polymer particle size were factors that contribute to reducing contraction of the resins.
\end{abstract}

Keywords: Pattern resin, Autopolymerization shrinkage, Lower contractile, Particle size, Programming

\section{INTRODUCTION}

Resin-based materials contract during polymerization, and deformation during the curing process is therefore inevitable ${ }^{1-3}$. This deformation can cause major problems in situations where high precision is required in clinical dental practice ${ }^{4,5}$. Therefore, various approaches have been attempted in order to develop materials and methods to reduce this shrinkage. One such material is pattern resin, which requires high precision. Pattern resin is mainly used for forming models of major connectors of removable partial dentures or inner crowns made of porcelain fused to metal crowns, which are uses that require high precision ${ }^{6}$. Pattern resin is more widely used because it has many advantages over wax, such as lower distortion, a lower coefficient of thermal expansion, and higher rigidity ${ }^{7,8}$. Pattern resin is also used for fixation of brazed parts to obtain the precise tooth-frame or long-span bridges ${ }^{9}$. In particular, many studies ${ }^{10-12)}$ have reported that distortion of superstructures can cause a problematic load on bone. Assif et al. ${ }^{13)}$ and other researchers ${ }^{14)}$ have reported that an osseointegrated implant has extremely limited movement of less than 10 $\mu \mathrm{m}$. Carr and Stewart $\left.{ }^{15}\right)$ have reported that the fitting of a full-arch implant framework made by one-piece casting exceeded the recommended level of fit needed to satisfy the passive fit requirement by more than a factor of 10 . This means that the brazing process is essential to make a full-arch framework. It is necessary to replace the pattern resin with metal solder after fixation, and no residue should remain after burnout. In other words, the pattern resin must be a high-precision material composed of only organic components.

Gibbs et al. ${ }^{16)}$ reported a photopolymerized pattern resin that is easy to handle and has a short fabrication time, although it has higher shrinkage values than autopolymerizing pattern resin. Ge et al. ${ }^{17)}$ and other researchers ${ }^{18,19)}$ reported some monomers that could reduce shrinkage. An obvious approach would be to increase the molecular weight of the monomers in order to decrease the concentration of reactive double bonds.

In 2018, a low-shrinkage autopolymerizing pattern resin was introduced. The shrinkage of autopolymerizing resin is considered to be related the amount of reactive double bonds in the bulk resin. In this study, we compared the dimensional change of various autopolymerizing resins and analyzed the effect of powder particle size and monomer components on dimensional change. The following hypothesis was examined in this experiment: As the concentration of the double bonds contained in the monomer contributing to curing of the novel pattern resin decreases, the shrinkage of the novel pattern resin becomes less than that of conventional autopolymerizing resins.

\section{MATERIALS AND METHODS}

\section{Materials}

The polymerization shrinkage characteristics of four autopolymerizing resins were determined. Lowshrinkage Pattern Resin (PRK; PRK101, GC, Tokyo, Japan) was the experimental material. The reference controls were the commercially available pattern resins GC Pattern Resin (GPR; GC) and Pi-Ku Plast (PIK; Bredent, Senden, Germany). Fixpeed (FIX; GC) -a low-shrinkage acrylic resin for fixation that contains inorganic fillers- was also used as a control material. Manufacturers and material information are listed in Table 1. Fifteen repeat measurements were made for each material. Data were statistically analyzed and 
Table 1 Materials tested

\begin{tabular}{lccc}
\hline \multicolumn{1}{c}{ Materials } & Code & Manufacturer & Batch number \\
\hline Novel Pattern Resin (PRK101) & PRK & GC, Tokyo, Japan & $\begin{array}{l}\text { Liquid lot 1708091G } \\
\text { Powder lot 1708081G }\end{array}$ \\
GC Pattern Resin & & & Liquid lot 1709121 \\
& GPR & GC & Powder lot 1711141 \\
Pi-Ku Plast HP36 & PIK & Bredent, Senden, Germany & Liquid lot 540 0021 2 \\
& & & Powder lot 540 0021 5 \\
FIXPEED & FIX & GC & Piquid lot1710021 \\
\end{tabular}

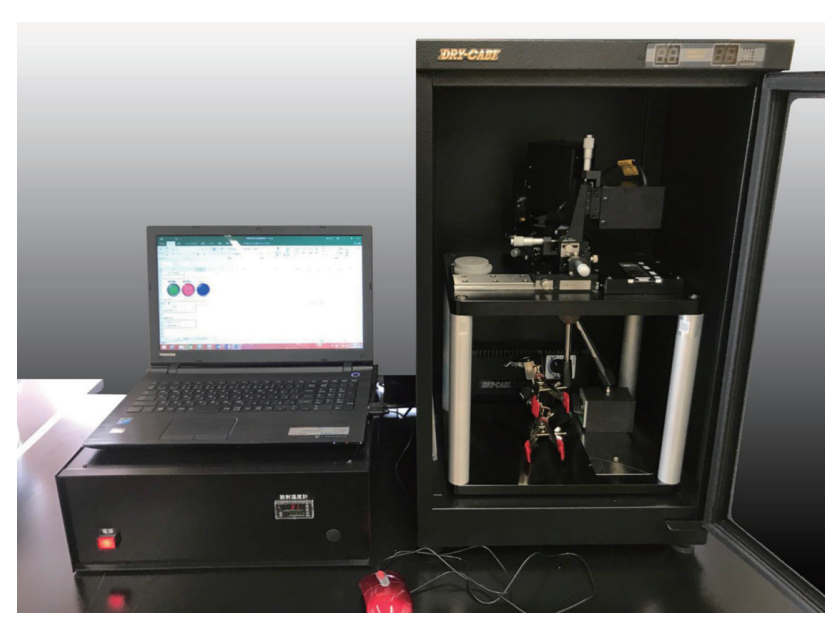

Fig. 1 Shrinkage measurement setup.

The experimental setup consisted of a laser displacement meter and a personal computer.

multiple comparisons were made using the TukeyKramer test with the level of significance set at $p<0.05$.

\section{Shrinkage measurement}

Measurements of linear polymerization shrinkage were performed using a dilatometer (CUSTRON, AcroEdge, Osaka, Japan) with a laser displacement meter (Fig. 1). A schematic of the shrinkage measurement apparatus is shown in Fig. 2(A). An unpolymerized specimen was placed in a cylindrical Teflon mold with an internal diameter of $10.0 \mathrm{~mm}$, an external diameter of $30.0 \mathrm{~mm}$, and a depth of $1.0 \mathrm{~mm}$, which was adhesively bonded onto a microscope slide (Fig. 2(B)). A schematic of the shrinkage measurements is shown in Fig. 2(C). Before the measurements, a microscope slide covered with blackened aluminum foil was used to adjust the zero point $\left(L_{0}\right.$ : distance between the laser source and foil surface). The aluminum foil sinks as the sample polymerizes and the amount of polymerization shrinkage can be measured by measuring the amount of transfer. The data acquisition rate was $1 \mathrm{~Hz}$. The percentage shrinkage was calculated by using Eq. (1).

$$
\text { Current shrinkage }(\%)=\frac{L_{\text {original }}-L_{\text {current }}}{L_{\text {original }}} \times 100
$$

Here, $L_{\text {original }}$ is the original specimen thickness $\left(L_{0}-L_{1}\right)$ and $L_{\text {current }}$ is the current thickness $\left(L_{0}-L_{2}\right)$.

In a preliminary trial, we found that a $\mathrm{P} / \mathrm{L}$ ratio of $1.0 \mathrm{~g}$ to $500 \mu \mathrm{L}$ gave a clinically manageable consistency. Flat blackened aluminum foil was placed over the unset specimen and an overlying rigid plate was used to press the foil into the upper surface of the ring. A working time of $60 \mathrm{~s}$ was allowed after the start of mixing before starting the shrinkage measurement and the measurement was continued for $10 \mathrm{~min}$ to obtain the final polymerization shrinkage. To calculate the shrinkage in the $\mathrm{X}$ and $\mathrm{Y}$ directions, the inner diameter of the Teflon mold before shrinkage measurement and the outer diameter of the cured sample were measured under a digital microscope (VHX-6000, Keyence, Osaka, Japan).

\section{Particle size measurement}

The powder morphology and particle size were observed by using scanning electron microscopy (SEM) and a custom-made program in Python using OpenCV (Open Source Computer Vision Library) functions for image processing. The surfaces of all specimens were sputtercoated with carbon for electrical conductivity. Elemental analysis was performed using a field-emission electron probe micro analyzer (JXA-8530FA, JEOL, Tokyo, Japan). Each micrograph magnification was chosen so that the particles shape could be distinguished.

The program flow chart is shown in Fig. 3. Some parts of the original SEM image were over-bright (Fig. 4, yellow arrows in original image). Averaging the histogram of the whole image causes loss of information in certain regions, especially over-bright parts. Hence, the image was processed using the contrast-limited adaptive histogram equalization (CLAHE) interpolation algorithm proposed by Zuiderveld ${ }^{20)}$, which uses histograms confined to a small region (Fig. 4, CLAHE image). The SEM image included a lot of fine grain noise. Median filtering was used for noise removal in pre-processing (Fig. 4, noise removal image). The filtered image was the input for circle detection using the Hough 
(A)

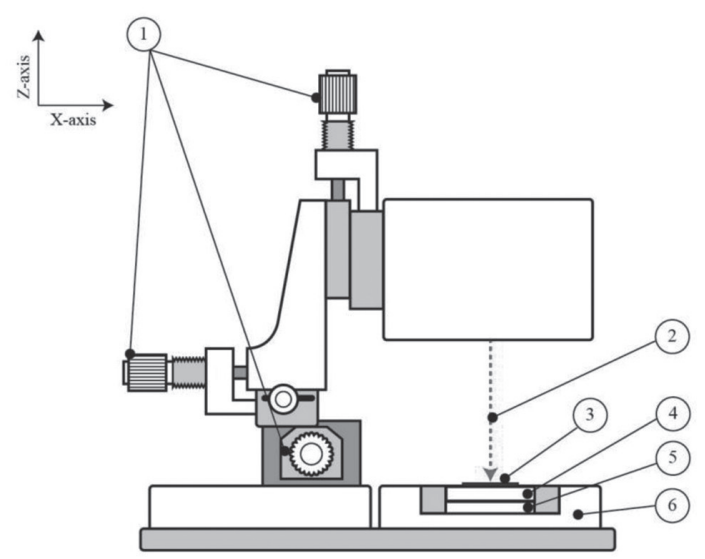

(B)

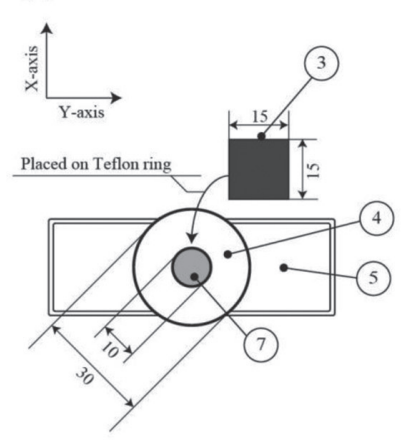

(C)

Fig. 2 Schematic of the polymerization contraction recording system. (A) Schematic of the shrinkage measurement assembly. (B) Plan view of the die. (C) Schematic of the shrinkage measuring method. 1: Screws for the three-dimensional linear movement stage. 2: Laser. 3: Blackened aluminum foil. 4: Cylindrical Teflon mold. 5: Glass plate. 6: Die holder. 7: Test specimen.

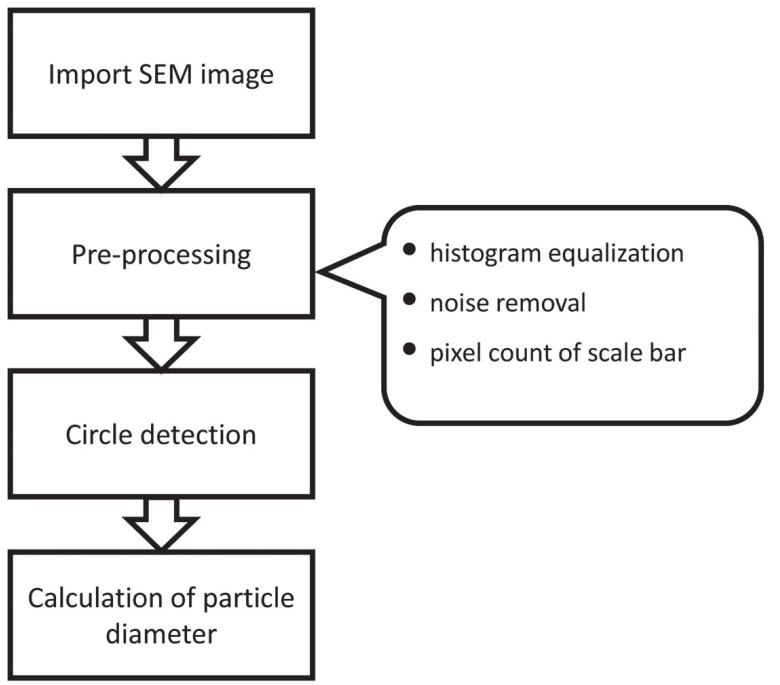

Fig. 3 Flowchart for the circle detection program. transform ${ }^{21-23)}$. The advantage of the Hough transform is that after detecting a circle, the information about its location and radius is known [Fig. 4, circle detection (Hough) image]. To calculate the particle sizes, the number of pixels in the scale bar (representing $100 \mu \mathrm{m}$ ) was counted. The particle diameter was divided into seven ranges. The percentage abundance ratios for each range were obtained by dividing the number in each range by the total number. The number of particles used for each measurement was 1,000 or more.

\section{Monomer components}

High-performance liquid chromatography/tandem mass spectrometry (LC-MS/MS; LCMS-8040, Shimadzu, Kyoto, Japan) was used to analyze the monomers. The monomers were separated with a YMC-Pack column (ODS-A/S-3 $\mu \mathrm{m} / 12$ nm, YMC, Kyoto, Japan) using a gradient program with $0.1 \%(\mathrm{v} / \mathrm{v})$ formic acid in distilled water and acetonitrile as solvents. Methyl methacrylate (MMA; MW=100.1), triethyleneglycol dimethacrylate (TEGDMA; MW=286.3), and ethylene 


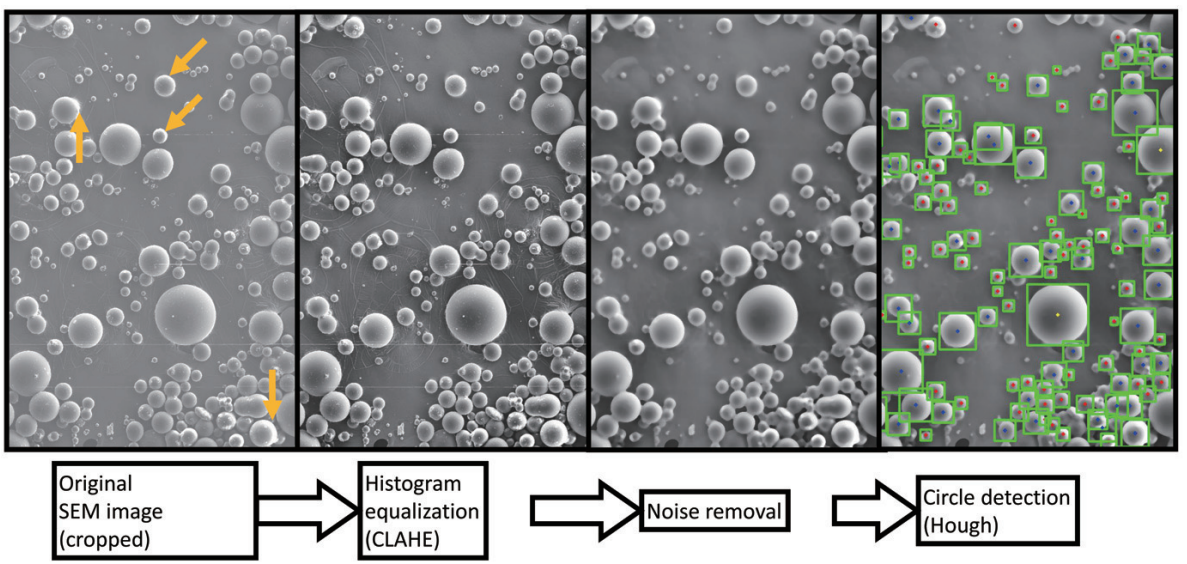

Fig. 4 Circle detection steps.

The SEM image of the PRK powder is used as an example. Yellow arrows indicate the over-bright parts in the original SEM image. The circle detection image is shown by the green rectangle, and the center is color coded according to size range: red for $0-20 \mu \mathrm{m}$, blue for $20-50 \mu \mathrm{m}$, and yellow for $50-100 \mu \mathrm{m}$.

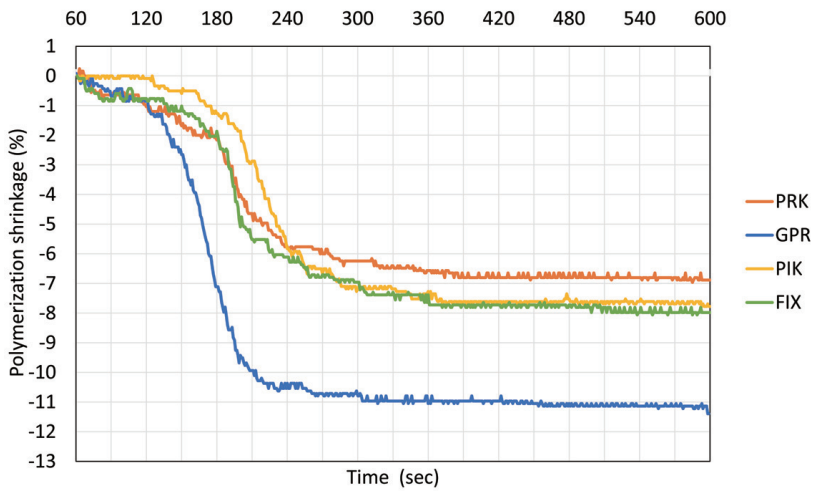

Fig. 5 Typical curve showing the time-dependence of shrinkage.

The $\mathrm{X}$-axis shows time (s) and the $\mathrm{Y}$-axis shows polymerization shrinkage (\%).

glycol dimethacrylate (EGDMA; MW=198.2) were used as reference standards. Each monomer sample was dissolved in acetone with the concentration of $1 \mu \mathrm{L} / \mathrm{mL}$. Monomers was identified by retention time and product ion scan experiments.

\section{RESULTS}

\section{Pattern resin shrinkage}

Contraction of the disk specimen pulled the central portion of the blackened aluminum foil down evenly. Representative time-dependent shrinkage curves are presented in Fig. 5. The initial polymerization shrinkage proceeded rapidly from approximately 150 to $200 \mathrm{~s}$ for GPR. In contrast, rapid shrinkage occurred mainly from around 180 to $210 \mathrm{~s}$ for PRK and FIX. The shrinkage in PIK started from around 210 to $240 \mathrm{~s}$, and the timing of

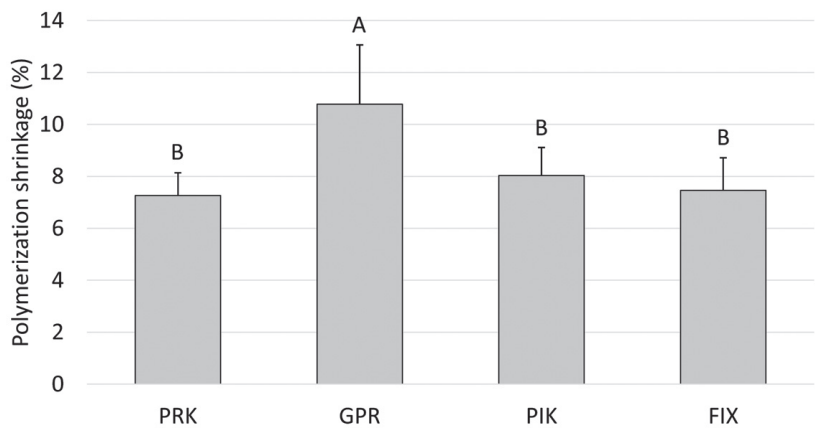

Fig. 6 Polymerization shrinkage at $10 \mathrm{~min}(\%)$. Letters in the bar indicate a significant difference $(p<0.05)$.

the shrinkage occurrence was the slowest of all samples. Over $80 \%$ of the shrinkage at $10 \mathrm{~min}$ had already occurred by $250 \mathrm{~s}$ for these materials. The shrinkage percentages at $10 \mathrm{~min}$ are presented in Fig. 6. Linear shrinkage reached $7.26 \pm 0.88$ for $\mathrm{PRK}, 10.78 \pm 2.28$ for GPR, $8.03 \pm 1.08$ for PIK, and $7.46 \pm 1.25 \%$ for FIX. The shrinkage of PRK was significantly lower than that of GPR. The shrinkage values were not significantly different among PRK, PIK, and FIX. The shrinkage in the $\mathrm{X}$ and $\mathrm{Y}$ directions is shown in Table 2. PRK tended to shrink less than the other three resins, though the differences were not significant.

\section{Particle size distribution of powder}

The powder morphologies of representative materials are shown in Fig. 7. The particle size distribution was determined from the SEM images and is displayed as the abundance ratio for each particle size bin in Fig. 8. The powder for GPR showed a broad particle size distribution with the maximum ratio (30\%) at 150 
Table 2 Shrinkage at direction of $\mathrm{X}$ and $\mathrm{Y}$ axis

\begin{tabular}{ccccc}
\hline & PRK & GPR & PIK & FIX \\
\hline Mean diameter $(\mathrm{mm})$ & $0.20(0.28)$ & $0.38(0.32)$ & $0.36(0.22)$ & $0.33(0.37)$ \\
\hline
\end{tabular}
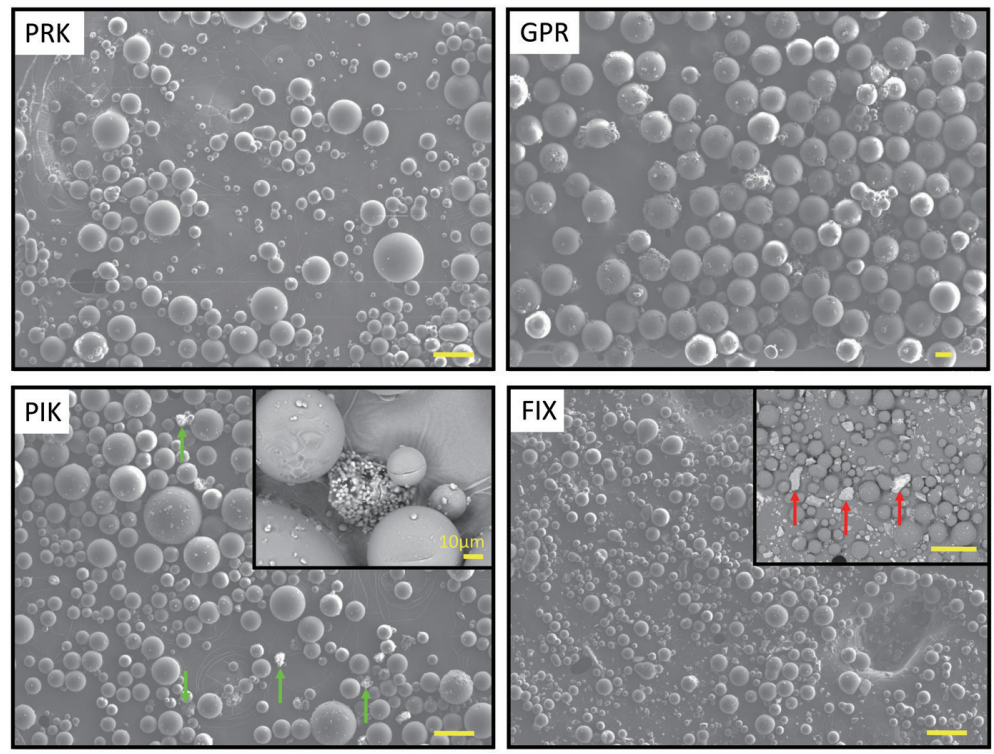

Fig. 7 SEM micrographs of the specimens.

The scale bar corresponds to $100 \mu \mathrm{m}$. Inset of FIX image: COMPO image of the particles that had a higher atomic number than the spherical structure (red arrow). Inset of PIK image: COMPO image of the particles that form an aggregate fine structure (green arrow).

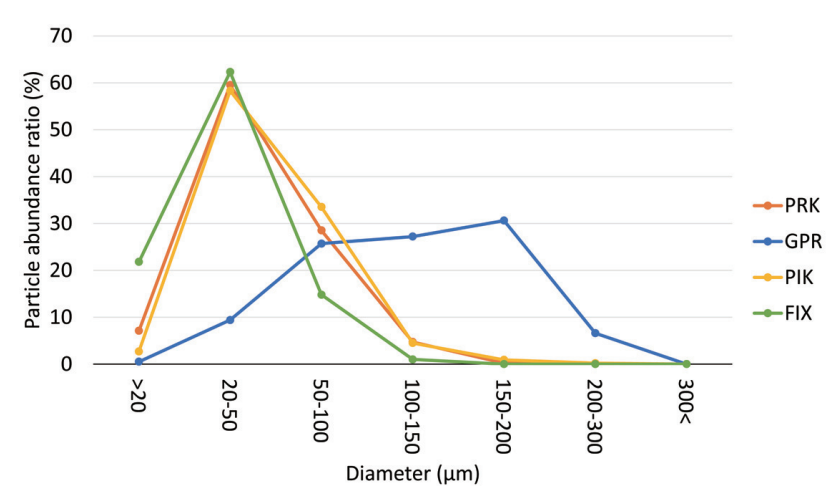

Fig. 8 Abundance distribution of each particle size range.

Particle abundance was calculated as the number of particles present in each range divided by the total number of analyzed particles.

$200 \mu \mathrm{m}$. In contrast, the powder for the other resins showed narrow distributions with the maximum ratios (around 60\%) shifted to 20-50 $\mu \mathrm{m}$. The particle size distributions agreed with the SEM micrographs, and the distribution became narrower as the amount of fine powder increased. A small amount of randomly cracked shape filler was detected in the SEM image of FIX (Fig. 7 , red arrow in FIX image inset). The filler was silicon (unpublished data), and the filler content was $2.4 \%$ as measured by the ash method. Most of PIK was composed of spherical organic structures, but aggregates of fine structures were observed in some places (Fig. 7, green arrow in PIK image inset). The fine structures contained elements heavy than carbon. The filler content of the aggregate materials was $0.5 \%$ or less as measured by the ash method. The GPR and PRK images contained only spheres composed of organic material.

\section{Monomer components}

The main monomer component in all the resins was MMA. LC-MS/MS suggested the presence of ethyl methacrylate $(m / z$ 113) in GPR. Similar monomer components were found in PRK and FIX, both of which contained EGDMA and a monomer with $\mathrm{m} / \mathrm{z} 338$. The product ion spectrum of the $\mathrm{m} / \mathrm{z} 338$ monomer consisted of three methacrylate groups $(\mathrm{m} / \mathrm{z} 86)$, and several ethylene groups and a $-\mathrm{CH}_{2} \mathrm{O}$ - group. The $\mathrm{m} / \mathrm{z} 338$ monomer content was higher in FIX than in PRK. In PIK, an $m / z 226$ monomer with two methacrylate groups was detected. The tertiary aromatic amines bearing ethyl groups $(\mathrm{m} / \mathrm{z} 221)$ and a small amount of benzoyl peroxide were detected at a 
retention time at $8.0 \mathrm{~min}$. The content of tertiary amines was lower in PIK than in the other three resins.

\section{DISCUSSION}

Pattern resins have been used for making prosthesis patterns because they have various advantages over wax, such as greater rigidity and lower distortion. However, even minor shrinkage in pattern resin can cause disruption when the material is used for precision work, such as fixation of a brazed part or prototype production of conus crowns ${ }^{4,6,24)}$. The time-dependent shrinkage curves showed that the shrinkage values of PRK were significantly lower than those of GPR and were in the same range as those of FIX and PIK, which contain filler to suppress shrinkage. Mojon et al. ${ }^{1)}$ reported that volumetric shrinkage was $7.9 \%$ for Duralay resin measured with a dilatometer, Rajagopal et $a l .^{8)}$ evaluated the contraction characteristics at the marginal gap. In addition, Gibbs et al. ${ }^{16)}$ measured volumetric shrinkage by calculating the contact area and found that the shrinkage of GPR was 5.7\%. Takahashi et al. ${ }^{18)}$ measured the percentage of linear shrinkage calculated from the protrusion of the specimen from the bottom of the cavity. Sato et al. ${ }^{25)}$ and other researchers ${ }^{26)}$ developed a method using a laser analog sensor to measure polymerization shrinkage of cold-curing resins. There are various other ways to measure the shrinkage of autopolymerizing resins ${ }^{27,28)}$. We used a measurement method based on a principle similar to the indirect method of Watts and Cash ${ }^{29}$. The surface contraction pattern induced in the aluminum foil reflected the shrinkage of disk specimens restricted to the vertical thickness dimension. This is in general agreement with the research of Feilzer et al. ${ }^{30}$, who found that that wallto-wall curing contraction in thin layers reached a value almost three times the linear polymerization shrinkage. Hence, the fractional linear shrinkage is approximately equivalent to the fractional volumetric shrinkage. The polymerization may have been inhibited by oxygen at the surface in contact with the Teflon mold, which has fine pores containing air. Therefore, except at the bottom surface in contact with glass, the force resisting contraction was assumed to be negligible. In addition, we assumed that the polymerization reaction in the center of each specimen was accelerated by heat accumulation. Thermal diffusion occurs around the periphery, slowing the polymerization reaction. The shrinkage also includes volumetric change due to temperature differences caused by the heat of polymerization. Consequently, the shrinkage was largest in the center of the mold and the shrinkage values obtained in this experiment were larger than those in previous research.

The contraction accompanying polymerization is affected by amount of monomer ${ }^{31}$. The theoretical value of polymerization contraction reaches $21.2 \%$ if all the $\mathrm{C}=\mathrm{C}$ bonds in the methyl methacrylate monomer are involved in polymerization ${ }^{32}$. The distance between molecules decreases to approximately $1.13 \AA$ when the $\mathrm{C}=\mathrm{C}$ bonds are converted to $\mathrm{C}-\mathrm{C}$ bonds by additional polymerization

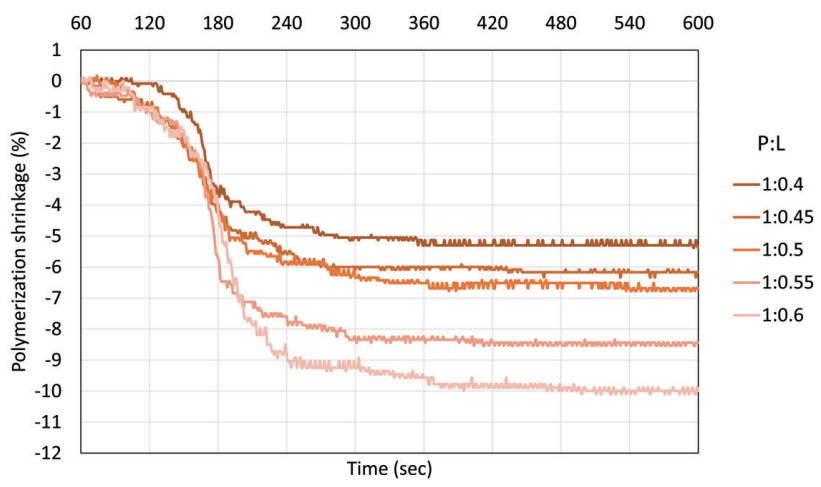

Fig. 9 Shrinkage of PRK using 5 different P:L ratios.

because of the van der Waals distance between vinyl monomers. Thus, it is important to know the amount of monomer molecules in the matrix, which cause the bulk contraction. In fact, the shrinkage decreased as the $\mathrm{P} / \mathrm{L}$ ratio was increased (Fig. 9). As seen from the structure of the monomer with lower shrinkage ${ }^{17-19)}$, increasing the molecular weight of the monomers decreases the contraction due to reactive double bonds. In general, monomers with a high molecular weight have high viscosity, and as a result, usability is remarkably worse. Mixture of monomers for pattern resin should maintain a balance between shrinkage and usability. The main monomer component of all the tested resins was MMA, and several polyfunctional monomers used as cross-linking reagent were detected in PRK, FIX, and PIK. PRK and FIX had similar components. Two kinds of cross-linking reagents were detected, one was EGDMA and the other was a monomer containing three functional group. For these monomers, the ratios of molecular weight to the number of monomer functional groups were 99 and 113, respectively. According to Fig. 5, the contraction curves of PRK and FIX showed similar behavior. In PIK, no trifunctional monomer was present, but a bifunctional monomer with $\mathrm{m} / \mathrm{z} 226$ was observed from product ion scan results. This monomer is predicted to be butylene glycol dimethacrylate, which has a central chain that is two carbons longer than that of EGDMA, for which the ratio of molecular weight to number of functional groups is 113 , equivalent to the trifunctional monomer noted above. All resins contained the same tertiary amines as polymerization accelerators. It is suggested that the polymerization reaction become slower because the amount of accelerator become lower. The amount of accelerator in PIK is the lowest of the four resins test, which is consistent with results in Fig. 5.

The abundance ratio of monomer to bulk material was calculated from the porosity of the powder bed. All of these polymers consisted of spheres and the smooth surface was in good agreement with the models proposed by Suzuki ${ }^{33)}$ and Ouchiyama and Tanaka ${ }^{34)}$ from SEM observations. The relationship between porosity and particle size was determined by measuring the abundance of particles in two particle size distributions 
Table 3 Average particle size and volume ratio of the filler in each particle size range

\begin{tabular}{|c|c|c|c|c|}
\hline \multirow{2}{*}{ Size range } & \multicolumn{2}{|c|}{ PRK } & \multicolumn{2}{|c|}{ GPR } \\
\hline & Mean diameter $(\mu \mathrm{m})$ & Total volume (\%) & Mean diameter $(\mu \mathrm{m})$ & Total volume (\%) \\
\hline$D p_{1}(<50 \mu \mathrm{m})$ & 30.59 & 28.9 & 36.78 & 0 \\
\hline$D p_{2}(50-150 \mu \mathrm{m})$ & 65.89 & 71.1 & 102.48 & 21.2 \\
\hline$D p_{3}(>150 \mu \mathrm{m})$ & - & - & 182.15 & 78.6 \\
\hline \multirow{2}{*}{ Size range } & \multicolumn{2}{|c|}{ PIK } & \multicolumn{2}{|c|}{ FIX } \\
\hline & Mean diameter $(\mu \mathrm{m})$ & Total volume (\%) & Mean diameter $(\mu \mathrm{m})$ & Total volume (\%) \\
\hline$D p_{1}(<50 \mu \mathrm{m})$ & 32.32 & 25.7 & 26.11 & 21.3 \\
\hline$D p_{2}(50-150 \mu \mathrm{m})$ & 66.76 & 74.3 & 68.43 & 78.7 \\
\hline$D p_{3}(>150 \mu \mathrm{m})$ & - & - & - & - \\
\hline
\end{tabular}

created for descriptive purposes. The particle size ranges and the average diameter of each range are shown in Table 3 . The powder packing rate, $D p_{\max }$, was calculated as the average value of the maximum particle diameter range, and the average value of the minimum range was $D p_{\min }$. Aikawa et $a l .^{35)}$ reported that the optimum conditions that would give the highest packing ratio are a particle size ratio of 8-12:50-110 $\mu \mathrm{m}$ at a mass ratio of 0.26:0.74. Suzuki et al. ${ }^{36,37)}$ and Ouchiyama and Tanaka ${ }^{38)}$ reported that the smallest void fraction area in a threecomponent random mixture of spheres appears on the coarse-fine axis in the isoporosity lines on triangular diagrams, which represent coarse, medium, and fine particles. The void fraction decreases because small particles occupy the gaps between the large particles as the width of the particle size distribution increases. For convenience, the volume ratio of each polymer obtained in this experiment was divided into three particle diameter ranges: 0 to $50 \mu \mathrm{m}$ for $D p_{1}, 50$ to $150 \mu \mathrm{m}$ for $D p_{2}$, and 150 to $300 \mu \mathrm{m}$ for $D p_{3}$. All specimens had two particle size ranges: $D p_{2}$ and $D p_{3}$ for GPR, and $D p_{1}$ and $D p_{2}$ for the other three specimens (Table 3). Each ratio was similar to that reported by Aikawa et al. ${ }^{35)}$. However, the larger the particle diameter ratio is, the higher the packing ratio $^{36)}$. The particle diameter ratio was 2.15 for PRK, 1.77 for GPR, 2.07 for PIK, and 2.62 for FIX; therefore, the packing ratio of PRK, PIK and FIX might be higher than that of GPR.

These polymers are composed of organic compounds, and thus during the wetting of the polymer surface with the monomer, the monomer diffused into the polymer and caused swelling. Vallittu and Ruyter ${ }^{39)}$ reported that the thickness of a swollen layer of polymethyl methacrylate (PMMA) was approximately $4.4 \mu \mathrm{m}$ at 3 min after methyl methacrylate was applied to a PMMA plate. This result suggested that a larger surface area contributes to reducing the amount of contraction due to the swelling of the polymer surface. The specific surface areas were compared assuming that the particles were smooth spheres. The specific surface areas increased as

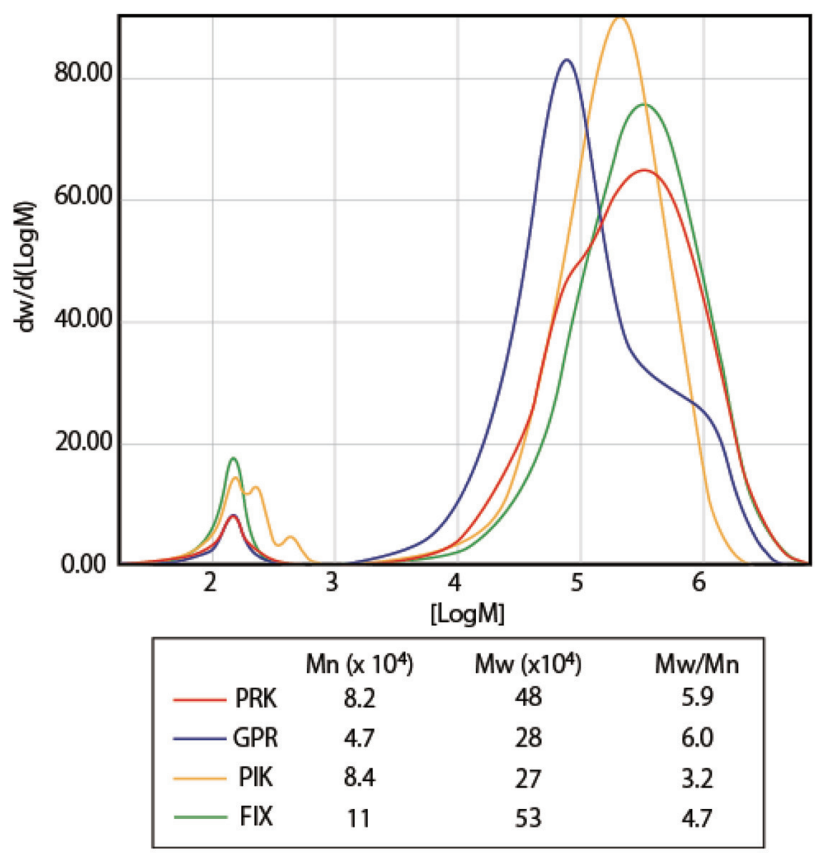

Fig. 10 Differential molecular weight distribution curves. Molecular weight distributions were determined by GPC using a high-performance liquid chromatography (HPLC) system (HLC-8220GPC, Tosoh, Tokyo, Japan) equipped with a GPC column (Shodex GPC KF-806L ×3, Showa Denko, Tokyo, Japan). The polystyrene equivalent molecular weight was used as a standard.

the powder particle size decreased. It is suggested that the surface area of organic filler is the largest in PRK because it had the largest total volume of $D p_{1}$ according to Table 3. Thus, it is considered that the swelling effect of the polymer surface was involved and contributed to the reduction of the contraction amount. In the timedependent shrinkage curves (Fig. 5), it can be seen that the time until the start of shrinkage was longer for FIX, 
PIK, and PRK than for GPR because of polymer surface swelling.

Moreover, Moraes et $a l^{40)}$ have reported the use of high molecular weight polymeric nanoparticles as a swellable, potentially reactive additive in a secondary monomer with the goal of reducing the overall reactive group concentration and thereby reducing polymerization shrinkage. In this investigation, the amount of unreacted chain ends was estimated from the molecular weight distribution by gel permeation chromatography (GPC). The differential molecular weight distribution, number-average molecular weight $(\mathrm{Mn})$, weight-average molecular weight $(\mathrm{Mw})$, and polydispersity $(\mathrm{Mw} / \mathrm{Mn})$ of each polymer are shown in Fig. 10. GPR had a smaller molecular weight than the other three polymers. GPR is thus expected to contain a larger number of chain ends (reactive double bonds) in the polymer, which is considered to be one reason why the amount of shrinkage was greater for GPR than for the other three resins. Overall, our hypothesis was partially supported. The novel pattern resin (PRK) showed significantly lower shrinkage than GPR, but the autopolymerizing acrylic resin for fixation (FIX) which included inorganic filler and a pattern resin containing a small amount of inorganic filler (PIK) exhibited shrinkage similar to that of PRK. Monomers that showed low shrinkage, namely, PRK, PIK, and FIX, included large molecules with several double bonds, and the abundance ratio of monomer to bulk was small; hence, the concentration of reactive double bonds was lower in these samples than in GPR. Controlling shrinkage by reducing the amount of double bonds has limitations. It should be noted that this approach may be expected to alter shrinkage in practical clinical use.

Polymerization shrinkage in materials such as denture base resin and composite resin is often clinically problematic ${ }^{2,3,41,42)}$, and it is desirable to reduce polymerization shrinkage. To reduce shrinkage in resin dental materials, this paper introduced some approaches involving the monomer components and the size and molecular weight of the polymer. The reduction of shrinkage by considering the factors described above will be helpful for developing materials with smaller polymerization shrinkage.

\section{REFERENCES}

1) Mojon P, Oberholzer JP, Meyer JM, Belser UC. Polymerization shrinkage of index and pattern acrylic resins. J Prosthet Dent 1990; 64: 684-688.

2) Davidson CL, Feilzer AJ. Polymerization shrinkage and polymerization shrinkage stress in polymer-based restoratives. J Dent 1997; 25: 435-440.

3) Ikeda T, Wakabayashi N, Ona M, Ohyama T. Effects of polymerization shrinkage on the interfacial stress at resinmetal joint in denture-base: A non-linear FE stress analysis. Dent Mater 2006; 22: 413-419.

4) Ness EM, Nicholls JI, Rubenstein JE, Smith DE. Accuracy of the acrylic resin pattern for the implant-retained prosthesis. Int J Prosthodont 1992; 5: 542-549.

5) Ferracane JL, Mitchem JC. Relationship between composite contraction stress and leakage in Class V cavities. Am J Dent
2003; 16: 239-243.

6) Brudvik JS, Lee S, Croshaw SN, Reimers DL. Laser welding of removable partial denture frameworks. Int J Prosthodont 2008; 21: 285-291.

7) Jörgensen KD, Ono T. Distortion of wax crowns. Eur J Oral Sci 1984; 92: 253-256.

8) Rajagopal P, Chitre V, Aras MA. A comparison of the accuracy of patterns processed from an inlay casting wax, an autopolymerized resin and a light-cured resin pattern material. Indian J Dent Res 2012; 23: 152-156.

9) Torsello F, Mirisola di Torresanto V, Ercoli C, Cordaro L. Evaluation of the marginal precision of one-piece complete arch titanium frameworks fabricated using five different methods for implant-supported restorations. Clin Oral Implants Res 2008; 19: 772-779.

10) Guichet DL, Yoshinobu D, Caputo AA. Effect of splinting and interproximal contact tightness on load transfer by implant restorations. J Prosthet Dent 2002; 87: 528-535.

11) Heckmann SM, Karl M, Wichmann MG, Winter W, Graef F, Taylor TD. Cement fixation and screw retention: parameters of passive fit - An in vitro study of three-unit implantsupported fixed partial dentures-. Clin Oral Implants Res 2004; 14: 466-473.

12) Vasant R, Vasant MK. Retention systems for implantretained overdentures. Dent Update 2013; 40: 28-31.

13) Assif D, Barry M, Avinoam S. Accuracy of implant impression techniques. Int J Oral Maxillofac Implants 1996; 11: 216222.

14) Carr AB, Gerard DA, Larsen PE. The response of bone in primates around unloaded dental implants supporting prostheses with different levels of fit. J Prosthet Dent 1996; 76: 500-509.

15) Carr AB, Stewart RB. Full-arch implant framework casting accuracy: Preliminary in vitro observation for in vivo testing. J Prosthodont 1993; 2: 2-8.

16) Gibbs SB, Versluis A, Tantbirojn D, Ahuja S. Comparison of polymerization shrinkage of pattern resins. J Prosthet Dent 2014; 112: 293-298.

17) Ge J, Trujillo M, Stansbury J. Synthesis and photopolymerization of low shrinkage methacrylate monomers containing bulky substituent groups. Dent Mater 2005; 21: 1163-1169.

18) Takahashi J, Kitahara K, Teraoka, F, Kubo F. Resin pattern material with low polymerization shrinkage. Int J Prosthodont 1999; 12: 325-329.

19) Yamazaki LC, Moraes AGD, Barros M, Lewis S, Francci C, Stansbury JW, Pfeifer CS. Polymerization development of "low-shrink" resin composites: Reaction kinetics, polymerization stress and quality of network. Dent Mater 2013; 29: e169-e179.

20) Zuiderveld K. Contrast limited adaptive histogram equalization. Graphic Gems IV. San Diego: Academic Press Professional. 1994: 474-485.

21) Ateş H, Gerek ÖN. An image-processing based automated bacteria colony counter. Proceeding of Computer and Information Sciences, 2009. ISCIS 2009. 24th International Symposium; 2009 Oct 14-16; Guzelyurt, Cyprus.

22) Pásztó P, Hubinský P. Application of a Visual System for mobile robot navigation (OpenCV). AT\&P J 2010; PLUS1: 6265.

23) Russell M, Fischaber S. OpenCV based road sign recognition on Zynq. Industrial Informatics (INDIN), 2013 11th IEEE International Conference on, 2013 July 29-31; Bochum, Germany.

24) Papaspyridakos P, Kim YJ, Finkelman M, El-Rafie K, Weber HP. Digital evaluation of three splinting materials used to fabricate verification jigs for full-arch implant prostheses: A comparative study. J Esthet Restor Dent 2017; 29: 102-109.

25) Sato T, Miyazaki M, Rikuta A, Kobayashi K. Application 
of the laser speckle-correlation method for determining the shrinkage vector of a light-cured resin. Dent Mater J 2004; 23: 284-290.

26) Tsuruta S, Morimoto K, Yamamoto I, Kawai T, Matsunami I. Measurement of polymerization shrinkage of cold-curing resin using laser analogue sensor. Aichi Gakuin Dent Sci 2005; 43: 635-639. (In Japanese)

27) Gee AJD, Feilzer AJ, Davidson CL. True linear polymerization shrinkage of unfilled resins and composites determined with a linometer. Dent Mater 1993; 9: 11-14.

28) Oberholzer TG, Grobler SR, Pameijer CH, Rossouw RJ. A modified dilatometer for determining volumetric polymerization shrinkage of dental materials. Meas Sci Technol 2002; 13: 78-83.

29) Watts DC, Cash AJ. Determination of polymerization shrinkage kinetics in visible-light-cured materials: method development. Dent Mater 1991; 7: 281-287.

30) Feilzer AJ, DE Gee AJ, Davidson CL. Increased wall-to-wall curing contraction in thin bonded resin layers. J Dent Res 1989; 68: 48-50.

31) Dewaele M, Truffier-Boutry D, Devaux J, Leloup G. Volume contraction in photocured dental resins: The shrinkageconversion relationship revisited. Dent Mater 2006; 22: 359365.

32) Endo T. Possibility to avoid shrinkage during polymerizationsynthesis of monomers that expand on polymerization. Polymers 1978; 27: 108-112. (In Japanese)

33) Suzuki M. Effect of particle properties on dense packing of powder. J Soc Powder Technol Jpn 2003; 40: 348-354. (In Japanese)

34) Ouchiyama N, Tanaka T. Porosity estimation from particle size distribution. Ind Eng Chem Fundam 1986; 25: 125-129.

35) Aikawa Y, Inoue M, Sakai E. Fundamental theory of void fraction of cohesive spheres with size distribution and its application to multi component mixture system. J Ceram Soc Jpn 2012; 120: 21-24.

36) Suzuki M, Yagi A, Watanabe T, Oshima T. Estimation of void fraction in a three component random mixture of spheres. Kagaku Kogaku Ronbunsyu 1984; 10: 721-727. (In Japanese)

37) Suzuki M, Ichiba H, Hasegawa I, Oshima T. Void fraction of multi-component randomly packed beds with size distributions. Kagaku Kogaku Ronbunsyu 1985; 11: 438-443. (In Japanese)

38) Ouchiyama N, Tanaka T. Porosity estimation for random packing of spherical particles. Ind Eng Chem Fundam 1984; 23: 490-493.

39) Vallittu PK, Ruyter IE. Swelling of poly(methyl methacrylate) resin at the repair joint. Int J Prosthodont 1997; 10: 254258.

40) Moraes R, Garcia JW, Barros MD, Lewis SH, Pfeifer CS, Liu J, Stansbury JW. Control of polymerization shrinkage and stress in nanogel-modified monomer and composite materials. Dent Mater 2011; 27: 509-519.

41) Tolidis K, Nobecourt A, Randall RC. Effect of a resin-modified glass ionomer liner on volumetric polymerization shrinkage of various composites. Dent Mater 1998; 14: 417-423.

42) Amirouche-Korichi A, Mouzali M, Watts DC. Effects of monomer ratios and highly radiopaque fillers on degree of conversion and shrinkage-strain of dental resin composites. Dent Mater 2009; 25: 1411-1418. 